\title{
sciendo
}

Current Issues in Pharmacy and Medical Sciences

Formerly ANNALES UNIVERSITATIS MARIAE CURIE-SKLODOWSKA, SECTIO DDD, PHARMACIA

journal homepage: http://www.curipms.umlub.pl/

\section{Susceptibility in vitro of clinical Candida albicans isolates to the selected azoles}

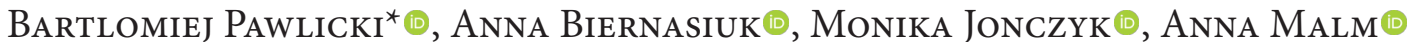

Department of Pharmaceutical Microbiology, Medical University of Lublin, Poland

\begin{tabular}{|c|c|}
\hline ARTICLE INFO & ABSTRACT \\
\hline & \multirow[b]{2}{*}{$\begin{array}{l}\text { Candida spp. is the most prevalent cause of fungalinfection worldwide, and their increasing } \\
\text { resistance to anti-fungal agents, especially to azoles, has become problematic. The aim of } \\
\text { this work was to establish the susceptibility to fluconazole, itraconazole, voriconazole } \\
\text { and posaconazole of } 50 \text { clinical C. albicans isolates from hematooncological patients. } \\
\text { This has been evaluated using the following parameters: MIC (Minimum Inhibitory } \\
\text { Concentration), MIC }{ }_{50} \text { (MIC required to inhibit the growth of } 50 \% \text { of organisms), as } \\
\text { well as } \text { MIC }_{90} \text { (MIC required to inhibit the growth of } 90 \% \text { of organisms). Susceptibility } \\
\text { of the studied clinical isolates to all azoles was high, being } 86 \% \text { for itraconazole, } 90 \% \text { for } \\
\text { fluconazole and posaconazole and } 92 \% \text { for voriconazole. The resistance rates ranged from } \\
8 \% \text { (voriconazole), to } 12 \% \text { (itraconazole). The emergence of azole-resistant yeast strains } \\
\text { creates a necessity to determine and monitor the sensitivity of the isolated Candida spp., } \\
\text { including C. albicans, especially in patients predisposed to life-threating fungal invasive } \\
\text { disease. }\end{array}$} \\
\hline $\begin{array}{l}\text { Keywords: } \\
\text { Candida albicans, } \\
\text { hematooncological } \\
\text { patients, } \\
\text { azoles, } \\
\text { resistance. }\end{array}$ & \\
\hline
\end{tabular}

\section{INTRODUCTION}

Candida, a genus of yeasts that belongs to the Saccharomycetales, is considered to be the most common cause of fungal infections worldwide [1]. A few hundred Candida species have been identified. Dozens of them are opportunistic pathogens, causing fungal infections named as 'candidiases', especially in patients with impaired immune systems, e.g. oncological and hematooncological patients. These infections include superficial lesions, affecting the skin or mucous membrane, or invasive, life-threatening diseases [2]. They have mainly an endogenic character because human microbiota can be regarded as the reservoir of Candida spp. [3]. The most commonly isolated pathogenic species is Candida albicans [4]. Although the diagnostic and treatment options have been improved, fungal infections, including candidiases, remain a problem, especially those being invasive diseases with high mortality [5].

Polyenes, fluoropyrimidines, echinocandins and azoles are antifungal agents used in Candida infections treatment [4]. Azoles are antifungals used globally to treat Candida spp. infections, as well as for preventive purposes [2]. These agents belong to the family of imidazole derivatives (e.g. clotrimazole, ketoconazole, miconazole) and triazole derivatives such as itraconazole, fluconazole, posaconazole and

\footnotetext{
* Corresponding author

e-mail:bp.pawlak@gmail.com
}

voriconazole [4,6]. Antifungal activity of azoles results from inhibition of the enzyme encoded by gene $E R G 11$, i.e. sterol 14alfa-demethylase, which takes part in the transformation of lanosterol into ergosterol. Therefore, these agents interrupt the biosynthesis of ergosterol - an important Candida spp. cell membrane compound, leading to inhibition of fungal growth. In addition, $14 \alpha$-methyl-3,6-diol, being a fungistatic compound, is accumulated inside the yeast cell [4].

Increasing resistance and multiresistance to antifungal agents has become more and more serious. The most predominant among Candida spp. is resistance to azoles, caused by the wide use of these medicines in the last decades in clinical practice - both for prophylactic and therapeutic purposes [1]. Candida spp. has evolved several resistance mechanisms against azoles. Among these are: point mutations in the gene ERG11 (interference in azoles binding), gene ERG11 up regulation (influence on ergosterol production), reduced azoles affinity to cell membrane, overexpression or amplification of multiple classes of drug efflux pumps (rapid azole extrusion from fungal cells), regulation of cellular stress response pathways and biofilm creation $[1,3]$.

The overall goal of this work was to determine the susceptibility to fluconazole, itraconazole, voriconazole and posaconazole of clinical C. albicans isolates from 
hematooncological patients in order to assess the prevalence of resistance to these azoles.

\section{MATERIALS AND METHODS}

The yeast population used in these studies included 50 C. albicans isolates. These microorganisms were from the collection of the Department of Pharmaceutical Microbiology, Medical University of Lublin, and were primarily isolated from clinical specimens obtained from hematooncological patients such as swabs from oral cavity, upper respiratory tract, cervix, vagina, urethra and ears, as well as sputum, blood, stool and urine. The isolates were identified by standard diagnostic methods. The Ethical Committee of the Medical University of Lublin approved the study protocol (No. KE-0254/75/2011).

The assay of sensitivity of clinical $C$. albicans isolates to fluconazole, itraconazole, voriconazole and posaconazole was performed using the commercial Sensititre YeastOne YO9 AST antifungal panel (Thermo Fisher Scientific) based on the broth microdilution method, allowing for the determination of minimal inhibitory concentration (MIC). This method enables the qualitative and quantitative evaluation of the MIC (Minimum Inhibitory Concentration).

All the used yeast isolates were stored at $-75^{\circ} \mathrm{C}$ in Sabouraud broth (bioMerieux) with the addition of 50\% glycerol. They were first subcultured on Sabouraud agar (bioMerieux) and incubated at $35^{\circ} \mathrm{C}$ for $24 \mathrm{~h}$. The yeast suspensions were then prepared in sterile water according to the manufacturer's instruction to obtain optical density corresponding to $0.5 \mathrm{Mc}$ Farland standard. The final inocula were prepared by adding $20 \mu \mathrm{L}$ of a given suspension into 11 $\mathrm{mL}$ of OneYeast broth to obtain a density of approximately 1.5-8 $\times 103$ CFU (Colony Forming Units)/mL. The 96-well plates with antifungal agents at serial two-fold concentrations (fluconazole: 0.12 to $256 \mathrm{mg} / \mathrm{L}$, itraconazole: 0.015 to $16 \mathrm{mg} / \mathrm{L}$, posaconazole: 0.008 to $8 \mathrm{mg} / \mathrm{L}$ and voriconazole: 0.008 to $8 \mathrm{mg} / \mathrm{L}$ ) were filled up by $100 \mu \mathrm{L}$ of the final inoculum and then incubated at $35^{\circ} \mathrm{C}$ for $24 \mathrm{~h}$. After incubation, a visual reading was made on the basis of changing the yeast growth indicator color from blue (negative) to red (positive). MIC was defined as the lowest concentration of the compound showing complete fungal growth inhibition. The experiments were performed in triplicate. The representative data are presented.

In these studies, MIC interpretative criteria $(\mathrm{mg} / \mathrm{L})$ for C. albicans, according to CLSI M27 (Clinical and Laboratory Standards Institute standard M27) were as follows: fluconazole - susceptible $(\leq 8)$, dose-dependent susceptible (16-32), resistant $(\geq 64)$; itraconazole - susceptible $(\leq 0.125)$, dose-dependent susceptible $(0.25-0.5)$, resistant $(\geq 1)$; posaconazole and voriconazole - susceptible $(\leq 1)$, dose-dependent susceptible (2) and resistant ( $\geq 4)$ [7].

\section{RESULTS}

The susceptibility of clinical C. albicans isolates was first determined to fluconazole, itraconazole, voriconazole and posaconazole. Table 1 presents the obtained data. The majority of these isolates were sensitive to all azoles within the range $86-92 \%$. The resistance rates ranged from 8 to $12 \%$. We identified one isolate $(2 \%)$ as susceptible to itraconazole, depending on dose.

Table 1. The rate of susceptibility of clinical C. albicans isolates to the selected azoles assessed by MIC determination

\begin{tabular}{|c|r|r|r|r|}
\hline \multirow{2}{*}{$\begin{array}{c}\text { Category } \\
\text { of sensitivity }\end{array}$} & \multicolumn{4}{|c|}{ Number (percentage) of isolates } \\
\cline { 2 - 5 } & Fluconazole & Itraconazole & Voriconazole & Posaconazole \\
\hline Sensitivity & $46(92 \%)$ & $43(86 \%)$ & $46(92 \%)$ & $45(90 \%)$ \\
\hline $\begin{array}{c}\text { Sensitivity } \\
\text { dependent on dose }\end{array}$ & $0(0 \%)$ & $1(2 \%)$ & $0(0 \%)$ & $0(0 \%)$ \\
\hline \begin{tabular}{c} 
Resistance \\
\hline
\end{tabular} & $4(8 \%)$ & $6(12 \%)$ & $4(8 \%)$ & $5(10 \%)$ \\
\hline
\end{tabular}

Subsequently, we established the range of MIC of each azole for both sensitive and resistant $C$. albicans isolates (Fig. 1). We found that the MIC of fluconazole for susceptible strains ranged from $\leq 0.12$ to $4 \mathrm{mg} / \mathrm{L}$, and about onethird of isolates was characterized by $\mathrm{MIC}=0.5 \mathrm{mg} / \mathrm{L}$. MIC for fluconazole-resistant isolates was estimated at $\geq 64 \mathrm{mg} / \mathrm{L}$ (Fig. 1a). According to the obtained data (Fig. 1b), MIC of itraconazole ranged within $\leq 0.015-0.5 \mathrm{mg} / \mathrm{L}$. In the case of this drug, we noted that for $50 \%$ of the isolates, $\mathrm{MIC}=$ $0.03 \mathrm{mg} / \mathrm{L}$. In turn, MIC for strains with sensitivity depending on itraconazole dose amounted to be $1 \mathrm{mg} / \mathrm{L}$, while for resistant isolates, MIC $\geq 16 \mathrm{mg} / \mathrm{L}$. Furthermore, we saw that the MIC of voriconazole against sensitive isolates was within the range $\leq 0.008-0.12 \mathrm{mg} / \mathrm{L}$ (Fig. 1c). Moreover, the most frequent $\mathrm{MIC}$ value was $\mathrm{MIC} \leq 0.015 \mathrm{mg} / \mathrm{L}$ found for $72 \%$ isolates. Voriconazole-resistant strains were characterized by $\mathrm{MIC}=16 \mathrm{mg} / \mathrm{L}$. In addition, our work revealed that the MIC of posaconazole for susceptible isolates were in the range of $\leq 0.008-0.06 \mathrm{mg} / \mathrm{L}$, and most isolates $(56 \%)$ were characterized by $\mathrm{MIC}=0.015 \mathrm{mg} / \mathrm{L}$. We also established that posaconazole-resistant strains possessed MIC $\geq 8 \mathrm{mg} / \mathrm{L}$ (Fig. 1d).
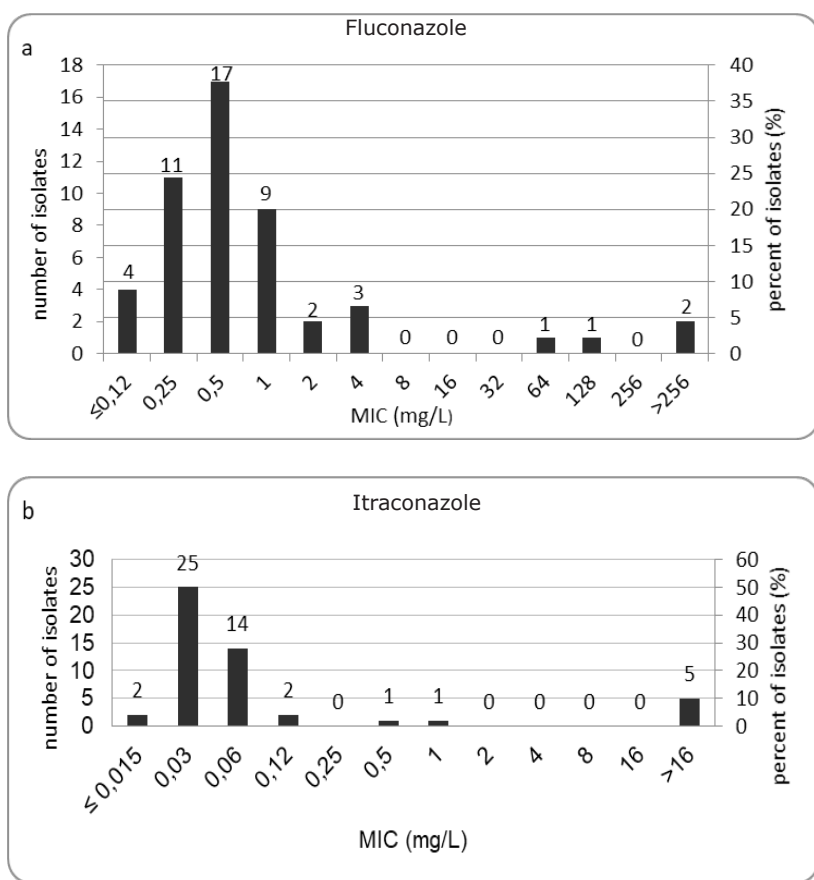

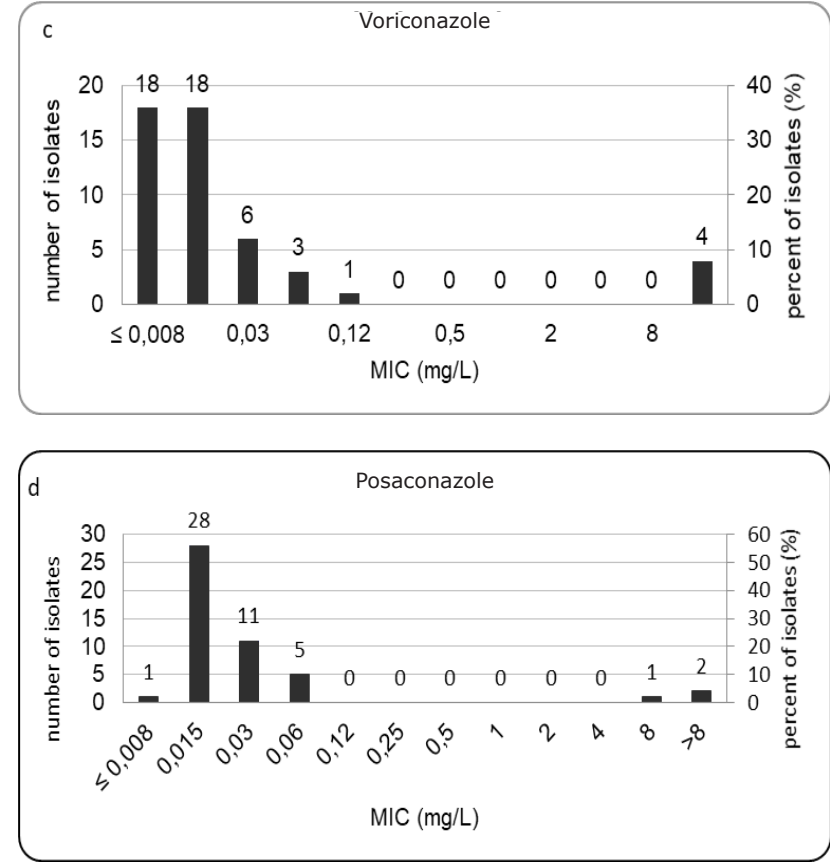

Figure 1. MIC (mg/L) range of fluconazole (a), itraconazole (b), voriconazole (c) and posaconazole (d) for clinical C. albicans isolates

From Table 2 it can be noted that the population parameters, i.e. $\mathrm{MIC}_{50}$ and $\mathrm{MIC}_{90}$ of the studied azoles, inhibiting $50 \%$ or $90 \%$ of C. albicans isolates, respectively, were within the range of values for sensitive strains.

Table 2. $\mathrm{MIC}_{50}$ and $\mathrm{MIC}_{90}(\mathrm{mg} / \mathrm{L})$ values for the selected azoles of clinical C. albicans isolates

\begin{tabular}{|c|c|c|}
\hline Azole & MIC $_{50}$ & MIC $_{90}$ \\
\hline Fluconazole & 0.5 & 4 \\
\hline Voriconazole & 0.015 & 0.06 \\
\hline Itraconaozle & 0.03 & 1 \\
\hline Posaconazole & 0.015 & 0.06 \\
\hline
\end{tabular}

\section{DISCUSSION}

In recent years, the number of fungal infections, both superficial and life-threatening invasive diseases, has increased. Candida spp., mainly C. albicans, is the major etiological agent of fungal infections [8]. However, it should be not forgotten that excessive use of antifungals may lead to the growing resistance of Candida species, including C. albicans. The consequence of resistance may be therapeutic failure. Therefore, the susceptibility of clinical isolates to antifungal agents should be identified, allowing more appropriate drugs to be introduced to the treatment course. Literature data shows that sensitivity and affirming the "60-90 rule" may help in the results of therapy prediction. This rule suggests that infections caused by susceptible pathogens respond to suitable therapy approximately to $90 \%$, while infections caused by resistant pathogens respond to suitable therapy only to $60 \%$ [9].

We found that the sensitivity of clinical C. albicans isolates from hematooncological patients to fluconazole, itraconazole, voriconazole and posaconazole was assessed at the high level, i.e. $86-92 \%$ with $\mathrm{MIC}_{90}$ being $4 \mathrm{mg} / \mathrm{L}, 0.06$ $\mathrm{mg} / \mathrm{L}, 1 \mathrm{mg} / \mathrm{L}$ and $0.06 \mathrm{mg} / \mathrm{L}$, respectively. The high sensitivity of clinical C. albicans isolates to azoles reported in this paper is in agreement with data presented by Lei et al. [10]. They found that fluconazole, itraconazole and voriconazole were highly active against clinical isolates of $C$. albicans, with $\mathrm{MIC}_{90}$ of $1 \mathrm{mg} / \mathrm{L}, 0.125 \mathrm{mg} / \mathrm{L}$ and $0.0625 \mathrm{mg} / \mathrm{L}$, while, about $90 \%$ isolates were susceptible to these azoles.

However, C. albicans can become resistant to azoles, especially to fluconazole, as this is frequently used to treat candidiases, mainly systemic infections [11]. The main mechanism of azole resistance in Candida spp. is related with increases in the number of efflux pumps in the cell due to gene overexpression [2]. We found that the resistance rate of clinical C. albicans isolates from hematooncological patients to fluconazole, itraconazole, voriconazole and posaconazole ranged from $8-12 \%$. According to literature data, C. albicans isolates from candidemic patients have the lowest incidence of azole resistance, including fluconazole $(0-5 \%)$ [11-14]. The incidence of fluconazole resistance in C. albicans isolates from oropharyngeal candidiasis was found to be higher, being above $10 \%$ [15]. However, studies performed by Yenisehirli et al. [16] showed that the overall resistance rates of C. albicans isolates to fluconazole, itraconazole, voriconazole and posaconazole were higher $34 \%, 21 \%, 14 \%$ and $14 \%$, respectively.

\section{CONCLUSIONS}

The present study shows that susceptibility of $C$. albicans isolates from hematooncological patients to posaconazole, voriconazole, itraconazole and fluconazole was high (86$92 \%)$. However, emergence of azole-resistant strains creates a necessity to determine and monitor sensitivity to the isolated Candida spp., especially in patients with lifethreating invasive disease.

\section{ORCID iDs}

Bartłomiej Pawlicki (Dhttps://orcid.org/0000-0003-4278-4168 Anna Biernasiuk (1)https://orcid.org/0000-0002-2844-9876 Monika Jończyk (D)https://orcid.org/0000-0001-7788-6266 Anna Malm (Dhttps://orcid.org/0000-0003-1503-7634

\section{REFERNCES}

1. Sharma J, Rosiana S, Razzaq I, Shapiro RS. Linking cellular morphogenesis with antifungal treatment and susceptibility in candida pathogens. J Fungi. 2019;21;5(1):17.

2. Pristov KE, Ghannoum MA. Resistance of Candida to azoles and echinocandins worldwide. Clin Microbiol Infect. 2019;25(7):792-8.

3. Staniszewska M, Bondaryk M, Kowalska M, Magda U, Łuka M, Ochal Z, et al. Pathogenesis and treatment of fungal infections by Candida spp. Postep Mikrobiol. 2014;53(3):229-40.

4. de Oliveira Santos GC, Vasconcelos CC, Lopes AJO, Cartágenes M do S, Filho AKDB, do Nascimento FRF, et al. Candida infections and therapeutic strategies: Mechanisms of action for traditional and alternative agents. Front Microbiol. 2018;9:1351-74.

5. Guinea J. Global trends in the distribution of Candida species causing candidemia. CMI. 2014;20(6):5-10.

6. Nami S, Aghebati-Maleki A, Morovati H, Aghebati-Maleki L. Current antifungal drugs and immunotherapeutic approaches as promising strategies to treatment of fungal diseases. Biomed Pharmacother. 2019;110:857-68. 
7. Karaaslan R, Aktaș E, Orhan F. An investigation of antifungal susceptibilities of the Candida species isolates from blood cultures using the sensititre yeastone microdilution method. Turk Hij ve Deney Biyol Derg. 2020;77(3):281-8.

8. Friedman DZP, Schwartz IS. Emerging fungal infections: New patients, new patterns, and new pathogens. J Fungi. 2019;5(3):67-86

9. Fazal F. European Committee on Antimicrobial Susceptibility Testing and Clinical and Laboratory Standards Institute breakpoints - the only point that matters in candidemia? J Thorac Dis. 2019;11(9):1412-14.

10. Lei J, Xu J, Wang T. In vitro susceptibility of Candida spp. to fluconazole, itraconazole and voriconazole and the correlation between triazoles susceptibility: Results from a five-year study. J Mycol Med. 2018;28(2):310-3.

11. Whaley SG, Berkow EL, Rybak JM, Nishimoto AT, Barker KS, Rogers PD. Azole antifungal resistance in Candida albicans and emerging non-albicans Candida Species. Front Microbiol. 2017;7:1-12.

12. Diekema D, Arbefeville S, Boyken L, Kroeger J, Pfaller M. The changing epidemiology of healthcare-associated candidemia over three decades. Diagn Microbiol Infect Dis. 2012;73(1):45-8.
13. Pfaller MA, Rhomberg PR, Messer SA, Jones RN, Castanheira M. Isavuconazole, micafungin, and 8 comparator antifungal agents' susceptibility profiles for common and uncommon opportunistic fungi collected in 2013: temporal analysis of antifungal drug resistance using CLSI species-specific clinical breakpoints and proposed epidemiological cutoff values. Diagn Microbiol Infect Dis. 2015;82(4):303-13.

14. Ying Y, Zhang J, Huang S, Liu F, Liu J, Zhang J, et al. Fluconazole susceptibility of 3,056 clinical isolates of Candida species from 2005 to 2009 in a tertiary-care hospital. Indian J Med Microbiol. 2015;1;33(3):413-5.

15. Enwuru C, Ogunledun A, Idika N, Enwuru N, Ogbonna F, Aniedobe M, et al. Fluconazole resistant opportunistic oropharyngeal candida and non-candida yeast-like isolates from HIV infected patients attending ARV clinics in Lagos, Nigeria. Afr Health Sci. 2008;8(3):142-8.

16. Yenisehirli G, Bulut N, Yenisehirli A, Bulut Y. In vitro susceptibilities of Candida albicans isolates to antifungal agents in Tokat, Turkey. Jundishapur J Microbiol. 2015;8(9):0-4. 